\title{
Efficacy, Acceptability and Two-Year Continuation Rate of Intrauterine Contraceptive Device Following Surgical or Medical Termination of First Trimester Pregnancy
}

\author{
Mohamed Rezk, MD ${ }^{1 *}$, Wael Gaber ${ }^{1}$, Haitham Hamza ${ }^{1}$, Mohamed Shawky ${ }^{2}$ \\ ${ }^{l}$ Department of Obstetrics and Gynecology, Faculty of Medicine, Menoufia University, Egypt \\ ${ }^{2}$ Department of Radiology, Faculty of Medicine, Menoufia University, Egypt
}

*Corresponding Author: Mohamed Rezk, Department of Obstetrics and Gynecology, Faculty of Medicine, Menoufia University, Egypt, Email:m_rezk9207@yahoo.com

\begin{abstract}
Objective: To assess the efficacy, acceptability and two-year continuation rate of intrauterine contraceptive device (IUCD) following surgical or medical termination of first trimester pregnancy.

Methods: This prospective observational study was conducted on 548 women with first trimester abortion who were divided into two groups; group 1underwent immediate insertion $(n=262)$ and group 1 underwent delayed insertion $(n=286)$. Adverse effects, acceptability and continuation rates were recorded at one month, 6 months, one and two years after insertion. Data was collected and analyzed.
\end{abstract}

Results: More patients in the delayed insertion group exhibited higher perception of pain, fainting, requested analgesia upon IUCD insertion and requested IUCD removal at one and two years follow up visits $(p<0.001)$. The rate of IUCD expulsion was higher in the immediate insertion group when compared to delayed insertion group (6.8\% versus $2.8 \%$, $p<0.05$ with Odds ratio 2.56 (1.1-6 at 95\% CI). The rates of abnormal bleeding, pelvic infection and perforation were no significantly different between the two groups $(p>0.05)$. The continuation rate was comparable in the two groups at one and six months ( $p>0.05)$ but was higher in the immediate insertion group at one year $(p<0.05)$ and two years follow up visits $(p<0.001)$. Patient acceptability was higher in the immediate insertion group at the follow up visits ( $p<0.001)$.

Conclusion: Although immediate versus delayed insertion of IUCD following medical or surgical termination of first trimester pregnancy was associated with a higher risk of expulsion, it has higher acceptability and continuation rates at one and two years.

Keywords: Intrauterine contraceptive device, medical abortion, surgical abortion, post abortion contraception, long acting reversible contraception.

\section{INTRODUCTION}

Provision of an effective and safe method of contraception should be implemented as an integrated part of any abortion care to prevent subsequent unplanned or unwanted pregnancy (1).

Intrauterine contraceptives device (IUCD) was shown to be highly effective to prevent unwanted pregnancy and repeat abortion compared with other methods of contraception when initiated early after abortion (2-6).

Previous studies have addressed disadvantages of immediate versus delayed insertion of copper IUCD after abortion with reported higher rates of expulsion or displacement following immediate insertion (7-10). However, earlier insertion of IUCD was associated with more women still using an IUCD at 6 months following abortion (7) and avoids loss of follow up of women scheduled for later insertion which reached to $42 \%$ (5).

The aim of this study was to assess the efficacy, acceptability and two-year continuation rate of intrauterine contraceptive device following surgical or medical termination of first trimester pregnancy.

\section{Materials And MethodS}

This prospective observational study was conducted at the department of Obstetrics and Gynecology in collaboration with Radiology 
department, Menoufia University hospital, Shibin El-Kom city, Menoufia governorate, Egypt in the period between September 2012 and September 2017.

This study was conducted according to the principles expressed in the Declaration of Helsinki and received appropriate ethical approval by the Menoufia Faculty of Medicine ethical committee with all participants signed an informed consent form following thorough explanation of the study objectives.

Patients presented with first trimester missed, spontaneous or incomplete abortions were candidates for medical or surgical termination of pregnancy and opting for copper-T 380 IUCD insertion, were eligible to participate.

Multiparous women presented with first trimester abortion who requested medical abortion for termination of pregnancy up to eight weeks (56 days) of gestation or surgical evacuation between 8-12 weeks' gestation, not planning for pregnancy in the near future, who desired long acting reversible contraception (LARC) and fulfilled the criteria for IUCD insertion were enrolled. Gestational age was determinded by the last menstrual period together with transvaginal sonographic (TVS) measurements of crown-rump length or gestational sac.

Women with septic abortion, known or suspected molar pregnancy, medical disorders, bleeding tendency, pelvic infection in the past three months, uterine abnormality as fibroids and any contraindication to IUCD insertion as well as those with failure of IUCD insertion were excluded from the study.

According to our hospital policy, medical termination was carried out by vaginal administration of misoprostol 200 ug every 4 hours till complete abortion obtained on site, while surgical evacuation was accomplished via suction evacuation under general anesthesia. All patients received prophylactic doxycycline 100 $\mathrm{mg} / 12$ hours during the entire period of termination.

Prior to IUCD insertion, TVS was performed to assure endometrial thickness less than $15 \mathrm{~mm}$ with absence of any remaining products of conception.

Sample size calculation was primarily based on the rate of IUCD expulsion of 2-9\% from the literature. Accordingly, 500 participants were needed for the study to have a power of $90 \%$ at 95\% confidence interval and alpha level of 0.05 . To compensate for possible drop out cases and non-evaluable data, we enrolled 570 participants.

Patients were divided into two groups based on their choices either immediate or delayed insertion of IUCD as follows:

Group 1 (Immediate Insertion Group): included 274 patients who requested immediate insertion of copper-T 380 IUCD following medical abortion or within 15 minutes after completion of the surgical procedure, and before discharge from the hospital. IUCD failed insertion in two patients with 10 patients lost to follow so 262 patients completed the study.

Group 2 (Delayed Insertion Group): included 296 patients who requested delayed insertion of IUCD after 2-6 weeks following abortion and received recommendations to abstain from sexual intercourse until insertion of the IUCD. IUCD failed insertion in two patients with eight patients lost to follow so 286 patients completed the study (Figure 1: The flow diagram).

Follow up visits in the outpatient clinic were scheduled after one month, 6 months, one and two years following insertion of IUCD. Patients with difficult follow up were contacted via phone calls and electronic mails to attend the visits.

\section{Outcome measures}

- Pain intensity was recorded on the visual analogue scale (VAS) ranging from zero to ten directly with points of $0=$ no pain at all and $10=$ the most distressing pain, after insertion of the IUCD before any use of analgesics.

- Adverse effects of IUCD as fainting, bleeding patterns, expulsion, pelvic pain, pelvic infections, perforation and request for removal. Menstrual calendars were used to record the days on which women suffered bleeding as recommended by the World Health Organization (WHO) with participants recorded bleeding in a diary for 4 weeks. Expulsion was defined as the presence of the IUCD within the cervical canal (partial) or the passage of the IUCD out of the cervix (complete). Pelvic infection was considered to be present in women with purulent vaginal discharge.

- Method acceptability in terms of overall discomfort, overall satisfaction and recommendation to other women. Acceptability was measured at the follow up visits. 
Efficacy, Acceptability and Two-Year Continuation Rate of Intrauterine Contraceptive Device Following Surgical or Medical Termination of First Trimester Pregnancy

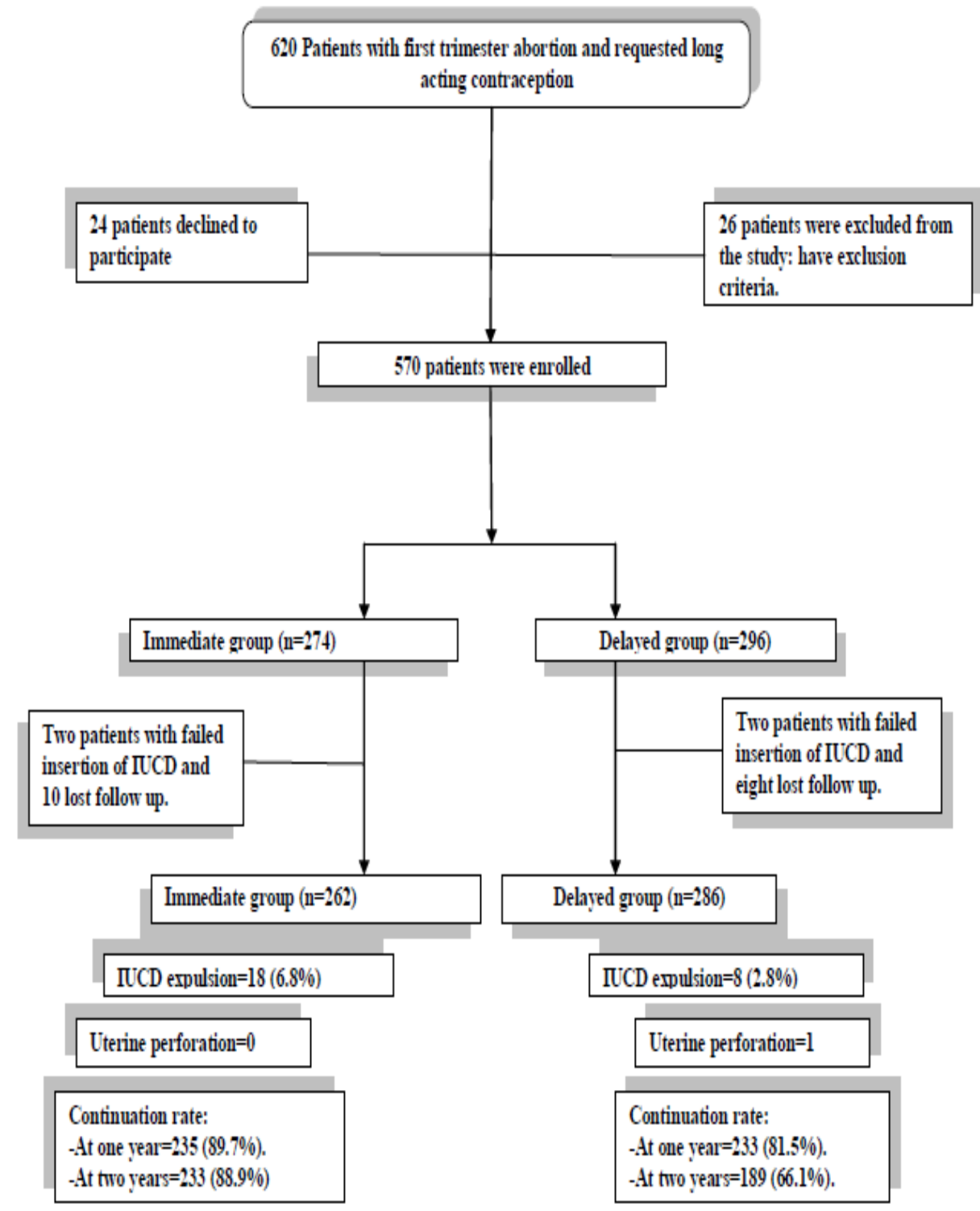

Figure1. Flow diagram of recruitment and retention of patients in the study

\section{Statistical ANAlysis}

Data was statistically analyzed by computer using SPSS version 22(SPSS Inc, Chicago, IL, USA). Parametric data was expressed as means and standard deviations with student t-test was used to compare between the two groups, while non-parametric data was expressed as number and percent with Chi-squared and Fischer's exact tests were used to compare categorical outcome where appropriate. $\mathrm{P}$ value $\leq 0.05$ was considered to indicate significance and $\mathrm{p} \leq 0.001$ was considered to indicate strong significance.

\section{RESUltS}

There was no significant difference between the two groups regarding age, parity, body mass index, gestational age, previous history of abortion or pelvic infection and endometrial thickness before IUCD insertion ( $p>0.05)$. More patients requested immediate IUCD insertion following medical termination $(p<0.001)$ as depicted in table (1)

Table1. Patients Characteristics

\begin{tabular}{|c|c|c|c|c|}
\hline & \begin{tabular}{|l|} 
Immediate \\
$(\mathbf{n = 2 6 2})$
\end{tabular} & 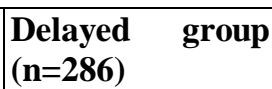 & \begin{tabular}{|l}
$\begin{array}{l}\text { Student t- } \\
\text { test }\end{array}$ \\
\end{tabular} & P-value \\
\hline Age (years) & $30.2 \pm 3.2$ & $29.8 \pm 3.4$ & 1.41 & $>0.05$ \\
\hline Parity & $2.7 \pm 1.3$ & $2.9 \pm 1.1$ & 1.95 & $>0.05$ \\
\hline Body mass index $\left(\mathrm{Kg} / \mathrm{m}^{2}\right)$ & $26.8 \pm 4.3$ & $27.1 \pm 4.7$ & 0.78 & $>0.05$ \\
\hline Gestational age (weeks) & $7.8 \pm 4.1$ & $7.6 \pm 4.2$ & 0.56 & $>0.05$ \\
\hline $\begin{array}{l}\text { Type of pregnancy termination: } \\
\text { Medical } \\
\text { Surgical }\end{array}$ & $\begin{array}{l}198(75.6 \%) \\
64(24.4 \%)\end{array}$ & $\begin{array}{l}98(34.3 \%) \\
188(65.7 \%)\end{array}$ & $92.3 \dagger$ & $<0.001$ \\
\hline
\end{tabular}


Efficacy, Acceptability and Two-Year Continuation Rate of Intrauterine Contraceptive Device Following Surgical or Medical Termination of First Trimester Pregnancy

\begin{tabular}{|l|l|l|l|l|}
\hline History of pelvic infection & $14(5.3 \%)$ & $18(6.3 \%)$ & $0.08 \dagger$ & $>0.05$ \\
\hline Previous abortion & $36(13.7 \%)$ & $44(15.4 \%)$ & $0.18 \dagger$ & $>0.05$ \\
\hline $\begin{array}{l}\text { Endometrial thickness before IUCD } \\
\text { insertion }\end{array}$ & $10.4 \pm 3.5$ & $10.2 \pm 3.6$ & 0.66 & $>0.05$ \\
\hline
\end{tabular}

†Chi square test

More patients in the delayed insertion group exhibited higher perception of pain, fainting, requested analgesia upon IUCD insertion and requested IUCD removal at one and two years follow up visits $(\mathrm{p}<0.001)$. The rate of IUCD expulsion was higher in the immediate insertion group when compared to delayed insertion Table2. Adverse effects of IUCD

\begin{tabular}{|c|c|c|c|c|l|}
\hline & $\begin{array}{c}\text { Immediate } \\
\text { group (n=262) }\end{array}$ & $\begin{array}{c}\text { Delayed group } \\
(\mathbf{n = 2 8 6})\end{array}$ & $\begin{array}{l}\text { Chisquare } \\
\text { test }\end{array}$ & P-value & $\begin{array}{l}\text { Odds ratio at } \\
\mathbf{9 5 \%} \text { CI }\end{array}$ \\
\hline Pain intensity (VAS) & $5.4 \pm 0.86$ & $6.5 \pm 1.4$ & $10.96 *$ & $<0.001$ & - \\
\hline Request for analgesia & $54(20.6 \%)$ & $102(35.6 \%)$ & 14.49 & $<0.001$ & $0.47(0.32-0.69)$ \\
\hline Fainting & $12(4.6 \%)$ & $38(13.3 \%)$ & 11.47 & $<0.001$ & $0.31(0.16-0.61)$ \\
\hline Perforation & 0 & $1(0.34 \%)$ & 0 & $>0.05$ & - \\
\hline Abnormal bleeding & $52(19.8 \%)$ & $58(20.3 \%)$ & 0.001 & $>0.05$ & $0.97(0.64-1.48)$ \\
Medical TOP & 44 & 42 & & & \\
Surgical TOP & 8 & 16 & & & \\
\hline IUCD expulsion: & $18(6.8 \%)$ & $8(2.8 \%)$ & 4.16 & $<0.05$ & $2.56(1.1-6)$ \\
Partial & 12 & 6 & & & \\
Complete & 6 & 2 & & & \\
\hline Pelvic infection: At one month & $12(4.5 \%)$ & $14(4.9 \%)$ & 0.010 .01 & $>0.05$ & $0.93(0.42-2.05)$ \\
6 months One year & $7(2.7 \%)$ & $9(3.1 \%)$ & $0.89 \dagger 0.64 \dagger$ & $>0.05$ & $0.84(0.31-2.3)$ \\
Two years & $2(0.76 \%)$ & $6(2.1 \%)$ & & $>0.05$ & $0.36(0.07-1.79)$ \\
& $1(0.38 \%)$ & $4(1.4 \%)$ & & $>0.05$ & $0.27(0.03-2.43)$ \\
\hline Request for removal: & $5(1.9 \%)$ & $8(2.8 \%)$ & 0.160 .34 & $>0.05$ & $0.68(0.22-2.09)$ \\
At one month 6 months & $6(2.2 \%)$ & $10(3.5 \%)$ & 15.5630 .7 & $>0.05$ & $0.65(0.23-1.81)$ \\
One year Two years & $8(3.1 \%)$ & $36(12.6 \%)$ & & $<0.001$ & $0.22(0.1-0.48)$ \\
& $6(2.3 \%)$ & $48(16.8 \%)$ & & $<0.001$ & $0.12(0.05-0.28)$ \\
\hline Re-insertion: & $6(2.2 \%)$ & $8(2.8 \%)$ & 0.01 & $>0.05$ & $0.81(0.28-2.38)$ \\
After expulsion & 3 & 4 & & & \\
After removal & 3 & 4 & & & \\
\hline Pregnancy rate during two & $4(1.5 \%)$ & $7(2.4 \%)$ & $0.21 \dagger$ & $>0.05$ & $0.62(0.18-2.14)$ \\
years & & & & & \\
\hline
\end{tabular}

*Student t-test, $†$ Fischer's exact test, VAS=Visual analogue scale

The continuation rate was comparable in the two groups at one and six months $(\mathrm{p}>0.05)$ but was higher in the immediate insertion group at group $(6.8 \%$ versus $2.8 \%, \mathrm{p}<0.05$ with Odds ratio $2.56(1.1-6$ at $95 \% \mathrm{CI})$. The rates of abnormal bleeding, pelvic infection and perforation were no significantly different between the two groups $(\mathrm{p}>0.05)$ as revealed in table (2). one year $(\mathrm{p}<0.05)$ and two years follow up visits $(\mathrm{p}<0.001)$ as shown in figure $(2)$.

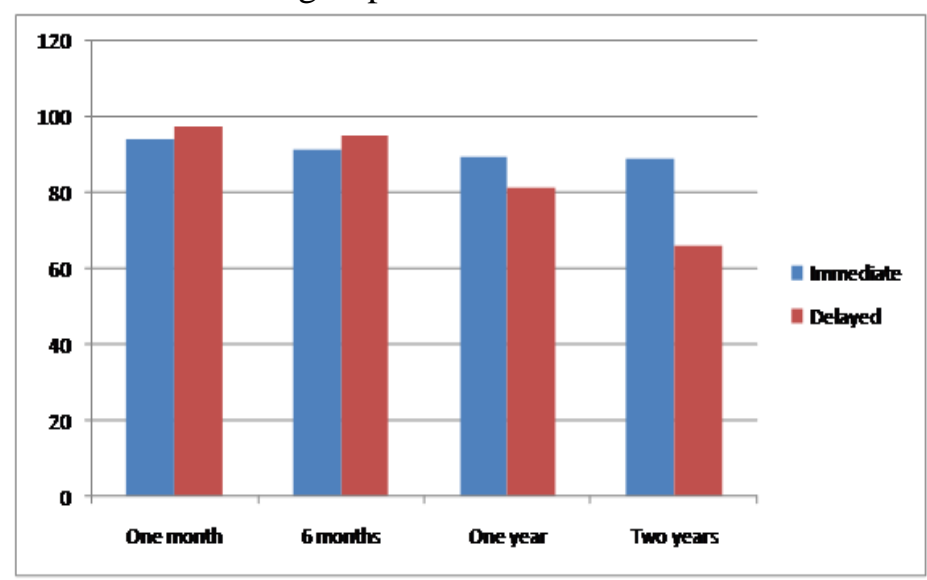

Figure2. Continuation rate of immediate versus delayed insertion of IUCD 
Efficacy, Acceptability and Two-Year Continuation Rate of Intrauterine Contraceptive Device Following Surgical or Medical Termination of First Trimester Pregnancy

Patient acceptability was higher in the immediate insertion group at one month, six months, one and two years follow up visits in Table3. Continuation rate and acceptability of IUCD terms of overall discomfort, overall satisfaction and recommendation to others $(\mathrm{p}<0.001)$ as shown in table (3).

\begin{tabular}{|c|c|c|c|c|c|}
\hline & $\begin{array}{c}\text { Immediate } \\
\text { group }(n=262)\end{array}$ & $\begin{array}{c}\text { Delayed group } \\
\quad(n=286)\end{array}$ & $\begin{array}{c}\text { Chi } \\
\text { square } \\
\text { test }\end{array}$ & P-value & $\begin{array}{c}\text { Odd's ratio at } \\
95 \% \mathrm{CI}\end{array}$ \\
\hline $\begin{array}{c}\text { Continuation rate: } \\
\text { At one month } \\
6 \text { months } \\
\text { One year } \\
\text { Two years }\end{array}$ & $\begin{array}{l}247(94.3 \%) \\
239(91.2 \%) \\
235(89.7 \%) \\
233(88.9 \%)\end{array}$ & $\begin{array}{l}279(97.5 \%) \\
272(95.1 \%) \\
233(81.5 \%) \\
189(66.1 \%)\end{array}$ & $\begin{array}{c}3.01 \\
2.69 \\
6.78 \\
39.03\end{array}$ & $\begin{array}{l}>0.05 \\
>0.05 \\
<0.05 \\
<0.001\end{array}$ & $\begin{array}{c}0.41(0.17-1.03) \\
0.53(0.27-1.06) \\
1.98(1.2-3.26) \\
4.12(2.61-6.51)\end{array}$ \\
\hline $\begin{array}{c}\text { Overall discomfort: } \\
\text { At one month } \\
6 \text { months } \\
\text { One year } \\
\text { Two years } \\
\end{array}$ & $\begin{array}{c}6(2.2 \%) \\
10(3.8 \%) \\
8(3.1 \%) \\
6(2.2)\end{array}$ & $\begin{array}{c}28(9.7 \%) \\
34(11.8 \%) \\
48(16.8 \%) \\
56(19.6 \%)\end{array}$ & $\begin{array}{c}11.96 \\
10.9 \\
26.6 \\
39.04\end{array}$ & $\begin{array}{l}<0.001 \\
<0.001 \\
<0.001 \\
<0.001\end{array}$ & $\begin{array}{c}0.22(0.17-0.74) \\
0.29(0.14-0.61) \\
0.16(0.07-0.34) \\
0.1(0.04-0.23)\end{array}$ \\
\hline $\begin{array}{c}\text { Overall satisfaction: } \\
\text { At one month } \\
6 \text { months } \\
\text { One year } \\
\text { Two years }\end{array}$ & $\begin{array}{l}256(97.8 \%) \\
252(96.2 \%) \\
254(96.9 \%) \\
256(97.8 \%)\end{array}$ & $\begin{array}{l}258(90.3 \%) \\
252(88.2 \%) \\
238(83.2 \%) \\
230(80.4 \%)\end{array}$ & $\begin{array}{c}11.96 \\
10.9 \\
26.6 \\
39.04\end{array}$ & $\begin{array}{l}<0.001 \\
<0.001 \\
<0.001 \\
<0.001\end{array}$ & $\begin{array}{c}0.22(0.17-0.74) \\
0.29(0.14-0.61) \\
0.16(0.07-0.34) \\
0.1(0.04-0.23)\end{array}$ \\
\hline $\begin{array}{c}\text { Recommendation to } \\
\text { others: } \\
\text { At one month } \\
6 \text { months } \\
\text { One year } \\
\text { Two years }\end{array}$ & $\begin{array}{l}250(95.4 \%) \\
244(93.1 \%) \\
238(90.8 \%) \\
246(93.9 \%)\end{array}$ & $\begin{array}{l}248(86.7 \%) \\
240(86.7 \%) \\
230(80.4 \%) \\
228(79.7 \%)\end{array}$ & $\begin{array}{c}11.47 \\
5.46 \\
11.09 \\
22.3\end{array}$ & $\begin{array}{l}<0.001 \\
<0.05 \\
<0.001 \\
<0.001\end{array}$ & $\begin{array}{c}3.19(1.63-6.25) \\
2.08(1.15-3.74) \\
2.41(1.45-4.03) \\
3.91(2.19-7)\end{array}$ \\
\hline
\end{tabular}

\section{DISCUSSION}

Delayed insertion of IUCD after abortion was associated with higher rates of immediate complications as pain, fainting, analgesic requirement as well as delayed complications like perforation in one case and request of IUCD removal at one and two years follow up visits.

Although, the rate of IUCD expulsion was higher in the immediate insertion group compared to delayed insertion group $(6.8 \%$ versus $2.8 \%$, with Odds ratio $2.56,1.1-6$ at $95 \%$ CI), patients experienced higher continuation rate at one year $(89.7 \%$ versus $81.5 \%)$ and two years $(88.9 \%$ versus $66.1 \%$ ) follow up with better acceptability of the method.

Our results are in accordance with previous studies which reported higher rate of IUCD expulsion with immediate insertion following abortion $(9,10)$.

In a previous observational study on 118 women who underwent insertion of IUCD 7-10 days following medical abortion, the rate of IUCD expulsion was $4.1 \%$ with displaced IUCD by ultrasound at 3 months follow up (9).

Among 575 women who were randomly assigned into immediate insertion of IUCD $(n=258)$ or delayed insertion $(n=226)$ after first trimester uterine aspiration, the 6-month expulsion risk was $5 \%$ after immediate insertion and $2.7 \%$ after delayed insertion (10).

More recently, the rate expulsion was12 (5.4\%) among 222 women who underwent delayed insertion of IUCD at 1-3 weeks after medical abortion (11).

In contrast to Shimoni et al, who reported comparable 6-month expulsion rate of $12 \%$ (8 of 69) in the immediate IUCD insertion group compared with $11 \%$ (7 of 65 ) in the delayed group after medical abortion (12).

Also, Sääv et al reported no difference in the 6month expulsion rate between early $(9.7 \%)$ versus delayed (7.4\%) insertion of IUCD after medical abortion (13).

A common disadvantageous practice with medical abortion is the delayed insertion of IUCD compared with surgical abortion which may discourage women from coming back to use IUCD (13).

While previous studies reported absence of uterine perforation or pelvic infections in their participants (9-13), the rate of pelvic infections 
in the current study was around 4\% in the first one month visit with one patient in the delayed insertion group experienced uterine perforation (Figure 3) that was diagnosed at the 6-month follow up visit and managed with laparoscopic removal of the IUCD
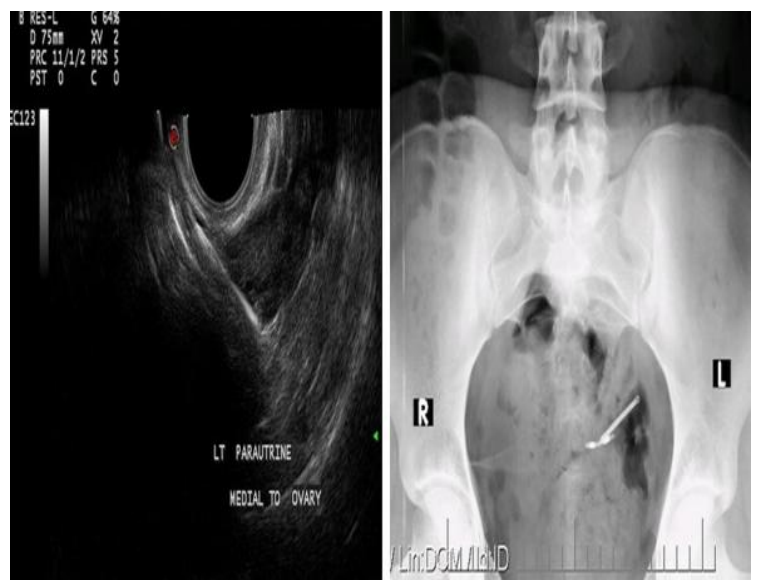

Figure3. Uterine perforation by IUCD in $P 2,32$ years woman in the delayed group with IUCD located in the left para-uterine region medial to the left ovary.

The 6-month continuation rate of IUCD was higher in the early insertion group compared to delayed insertion as reported by previous studies (10-12) which was confirmed at longer intervals (one and two years) in the current study.

Only one previous study reported the acceptability of IUCD inserted after abortion and was conducted on 300 women with actual acceptance rate of $44 \%$ at 10 weeks after insertion (14).

Inclusion of large number of patients who underwent either medical or surgical abortion together with the longer follow up period and high patient response rate constitute the main strength of this study. Inability to conduct a randomized trial was the main limitation of the current study.

Larger multicenter studies are warranted to draw the actual risk of expulsion of IUCD inserted immediately after first trimester abortion and to report rare but meaningful complications as uterine perforation.

Immediate insertion of IUCD following first trimester abortion generally has low complication rate and slightly higher expulsion rate with higher continuation and acceptability rates over two years.
Health care providers should recommend the initiation of IUCD as early as possible after first trimester abortion.

\section{CONClusion}

Although immediate versus delayed insertion of IUCD following medical or surgical termination of first trimester pregnancy was associated with a higher risk of expulsion, it has higher acceptability and continuation rates at one and two years.

\section{REFERENCES}

[1] Faúndes A. Strategies for the prevention of unsafe abortion. Int J Gynecol Obstet.2012; 119(Suppl. 1):S68-71.

[2] Goodman S, Hendlish SK, Reeves MF, et al.: Impact of immediate postabortal insertion of IUC on repeat abortion. Contraception 2008; 78:143-148.

[3] Heikinheimo O, Gissler M, Suhonen S: Can the outcome of the next pregnancy be predicted at the time of induced abortion? Hum Reprod.2009; 24: 820-826.

[4] Roberts H, Silva M, Xu S: Post abortion contraception and its effect on repeat abortion in Auckland, New Zealand. Contraception 2010; 82: 260-265.

[5] Grimes DA, Lopez LM, Schulz KF, et al.: Immediate postabortal insertion of intrauterine devices. Cochrane Database Syst Rev.2010; 6. CD001777.

[6] Winner B, Peipert JF, Zhao Q, et al.: Effectiveness of long-acting reversible contraception. N Engl J Med.2012; 366: 19982007.

[7] Gillett PG, Lee NH, Yuzpe AA, et al.: A comparison of the efficacy and acceptability of the Copper-7 intrauterine device following immediate or delayed insertion after firsttrimester therapeutic abortion. FertilSteril.1980; 34: 121-124.

[8] Pakarinen $\mathrm{P}$, Toivonen $\mathrm{J}$, Luukkainen $\mathrm{T}$ : Randomized comparison of levonorgestrel- and copper-releasing intrauterine systems immediately after abortion, with 5 years' follow-up. Contraception 2003; 68: 31-34.

[9] Betstadt SJ, Turok DK, Kapp N, Feng KT, Borgatta L: Intrauterine device insertion after medical abortion. Contraception 2010; 83: 517 521.

[10] Bednarek PH, Creinin MD, Reeves MF, et al.: Immediate versus delayed IUD insertion after uterine aspiration. N Engl J Med.2011; 364: 2208-2217. 
Efficacy, Acceptability and Two-Year Continuation Rate of Intrauterine Contraceptive Device Following Surgical or Medical Termination of First Trimester Pregnancy

[11] Pohjoranta E, Suhonen S, Mentula M et al.: Intrauterine contraception after medical abortion: factors affecting success of early insertion. Contraception. 2017; 95(3):257-262.

[12] Shimoni N, Davis A, Ramos ME et al.: Timing of copper intrauterine device insertion after medical abortion: a randomized controlled trial. Obstet Gynecol. 2011; 118(3):623-8.
[13] Sääv I, Stephansson O, Gemzell-Danielsson K. Early versus delayed insertion of intrauterine contraception after medical abortion - a randomized controlled trial. PLoS One. 2012; 7(11):e48948.

[14] El Tagy A, Sakr E, et al.: Safety and acceptability of post-abortal IUD insertion and the importance of counseling. Contraception 2003;67(3):229-34

Citation: Mohamed Rezk, Wael Gaber, Haitham Hamza, Mohamed Shawky. Efficacy, Acceptability and TwoYear Continuation Rate of Intrauterine Contraceptive Device Following Surgical or Medical Termination of First Trimester Pregnancy. ARC Journal of Gynecology and Obstetrics 2017; 2(4):11-16. DOI: dx.doi.org/10.20431/2455-9792.0204003

Copyright: (c) 2017 Authors. This is an open-access article distributed under the terms of the Creative Commons Attribution License, which permits unrestricted use, distribution, and reproduction in any medium, provided the original author and source are credited. 